\title{
Phylogeography, population history and conservation genetics of jaguars (Panthera onca, Mammalia, Felidae)
}

\author{
EDUARDO EIZIRIK, *† JAE-HEUP KIM, * MARILYN MENOTTI-RAYMOND,* \\ PETER G. CRAWSHAW JR. $\ddagger$ STEPHEN J. O’BRIEN* and WARREN E. JOHNSON* \\ *Laboratory of Genomic Diversity, National Cancer Institute - FCRDC, Frederick, MD 21702-1201, USA, +Department of Biology, \\ University of Maryland at College Park, USA, ‡CENAP/IBAMA, C.P. 295, Araçoiaba da Serra, SP 18190-000, Brazil
}

\begin{abstract}
The jaguar (Panthera onca), the largest felid in the American Continent, is currently threatened by habitat loss, fragmentation and human persecution. We have investigated the genetic diversity, population structure and demographic history of jaguars across their geographical range by analysing 715 base pairs of the mitochondrial DNA (mtDNA) control region and 29 microsatellite loci in $\approx 40$ individuals sampled from Mexico to southern Brazil. Jaguars display low to moderate levels of mtDNA diversity and medium to high levels of microsatellite size variation, and show evidence of a recent demographic expansion. We estimate that extant jaguar mtDNA lineages arose 280 000-510 000 years ago (95\% CI 137 000-830 000 years ago), a younger date than suggested by available fossil data. No strong geographical structure was observed, in contrast to previously proposed subspecific partitions. However, major geographical barriers such as the Amazon river and the Darien straits between northern South America and Central America appear to have restricted historical gene flow in this species, producing measurable genetic differentiation. Jaguars could be divided into four incompletely isolated phylogeographic groups, and further sampling may reveal a finer pattern of subdivision or isolation by distance on a regional level. Operational conservation units for this species can be defined on a biome or ecosystem scale, but should take into account the historical barriers to dispersal identified here. Conservation strategies for jaguars should aim to maintain high levels of gene flow over broad geographical areas, possibly through active management of disconnected populations on a regional scale.
\end{abstract}

Keywords: conservation, evolution, microsatellites, mitochondrial DNA, Panthera onca

Received 23 March 2000; revision received 16 August 2000; accepted 16 August 2000

\section{Introduction}

The jaguar (Panthera onca) is the largest Neotropical felid, measuring up to $2 \mathrm{~m}$ in total length and weighing up to $120 \mathrm{~kg}$ (Kitchener 1991). It is closely related to the other four big cats in the genus Panthera (Salles 1992; Johnson \& O'Brien 1997), and is the only extant representative of this genus in the Americas. It appears to have diverged from a common ancestor with the other Panthera species at least 1.5 million years ago (Ma) and entered the American continent through Beringia in the early Pleistocene (Turner \& Antón 1997). Jaguar fossils have been reported in North America as far north as Nebraska and Washington

Correspondence: Warren E. Johnson. Fax: (1301) 846 6327; E-mail: johnsonw@mail.ncifcrf.gov
(Seymour 1989; Turner \& Antón 1997), the oldest definitive specimens dating from approximately 850000 years ago (K. Seymour, personal communication).

In historical times jaguars ranged from the southern USA throughout Central and South America to the Argentinean Patagonia. Since the mid-1900s, however, they have been extirpated from broad portions of their original distribution and currently subsist in fragmented populations of variable size (Nowell \& Jackson 1996). Jaguars occur in habitats ranging from dense rainforest to more open scrubland and seasonally flooded marshes, and prey mainly on large mammals such as peccary, deer, tapir, and capybara, and in some areas also on reptiles such as turtles and caiman (Oliveira 1994). Around human agricultural lands they often prey on livestock, which generates chronic conflicts with ranchers and widespread 
persecution of this species in many regions. Although jaguars have been heavily hunted in the past as a trophy or for their pelts, their survival is currently threatened mostly by severe loss and fragmentation of habitat and direct persecution by ranchers (Nowell \& Jackson 1996). The species as a whole is currently listed in Appendix I (endangered species) of the Convention on International Trade of Endangered Species of Wild Fauna and Flora (CITES), and is considered to be vulnerable by IUCN (Wozencraft 1993). Some remnant populations, however, are known to be small and isolated, and can be considered to be severely endangered (Medellín et al., in press).

In order to devise adequate conservation and management strategies for an endangered species, it is important to incorporate a reliable understanding of its population structure and history, the existence of demographic partitions throughout its geographical range, and a characterization of the distribution of its genetic diversity (Avise 1989;
O'Brien 1994). Jaguars are currently divided into eight subspecies based on classical studies of morphology (reviewed by Seymour 1989), but a recent revision of skull characters found no significant geographical differentiation in these traits (Larson 1997). However, there has been no comparable attempt to describe the geographical distribution of genetic diversity in jaguars, nor to use molecular markers to clarify its population structure and evolutionary history.

In the present paper, we report a study of genetic variation in jaguars sampled throughout their geographical range, applying mitochondrial DNA (mtDNA) control region sequences and microsatellite loci size variation to address issues of phylogeography and population history in this species. Results from phylogenetic and population genetic analyses of these data are used to draw inferences on past demographic processes, clarify taxonomic issues, and provide insight relevant for conservation efforts.

Table 1 Samples of Panthera onca analysed in the present study

\begin{tabular}{|c|c|c|}
\hline ID & Geographic Origin & Institution/Contact \\
\hline Pon16 & Guatemala & ARCAS \\
\hline Pon20 & Chepo, Panama Prov., Panama & Summit Zoo \\
\hline Pon21 & Upala, Alajuela Prov., Costa Rica & Las Pumas \\
\hline Pon22 & Puerto Limon Prov., Costa Rica & Simon Bolivar Zoo \\
\hline Pon23 & Atlantico Sur Department, Nicaragua & Juigalpa Zoo \\
\hline Pon24 & Nicaragua & Radio Antenna, Managua \\
\hline Pon25 & Rio San Juan Department, Nicaragua & Managua Zoo \\
\hline Pon26 & Guatemala & Aurora Zoo \\
\hline Pon28 & Peru (Probably) & Mendoza Zoo \\
\hline Pon29 & Southern South America (Probably) & Montevideo Zoo \\
\hline Pon30 & Yucatan State, Mexico & Proyecto Balam \\
\hline Pon31 & San Luis Potosi State, Mexico & Leon Zoo \\
\hline Pon $34 \bullet, 35 \bullet$ & Mexico, unknown State & Cd.Victoria Zoo, Aragon Zoo \\
\hline Pon37 & Yucatan State, Mexico & Zoologico Centenario \\
\hline Pon $40^{*}, 41,42,44$ & Mato Grosso do Sul State, SW Brazil & Proj. Carnívoros, CENAP/IBAMA \\
\hline Pon43 & P.N. Iguaçu, Paraná State, S Brazil & Proj. Carnívoros, CENAP/IBAMA \\
\hline Pon46 & Goiás State, Brazil & Zoológico de Goiânia \\
\hline Pon47 & Pará State, N Brazil & Zoológico de Goiânia \\
\hline Pon $48^{\bullet}$ & Brazil, unknown State & Zoológico de Goiânia \\
\hline Pon $49,50 \bullet$ & Chaco, Paraguay & Itaipu, Paraguay \\
\hline Pon51, 52 & Jalisco State, Mexico & Idaho State University \\
\hline Pon54• & Amazonas State, Venezuela & Las Delicias \\
\hline Pon $56^{*}, 58$ & Falcon State, Venezuela & Las Delicias \\
\hline Pon59 & Barinas State, Venezuela & Asociacion Ganaderas \\
\hline Pon60 & Bolivar State, Venezuela & Merida \\
\hline Pon61 & Venezuela, unknown State & Barquisimento \\
\hline Pon62•, 63 & Bolivar State, Venezuela & Valencia Castellito \\
\hline Pon64 & Sta. Cruz Department, Bolivia & Zoologico de Santa Cruz \\
\hline Pon65, 66 & N. Bolivia & Zoologico de Santa Cruz \\
\hline Pon67• & Venezuela, unknown State & PROFAUNA \\
\hline Pon68 & French Guiana & Prog. Faune Sauvage/J.C. Vié \\
\hline Pon71 & Brazil, unknown State & Zoológico de Paranaguá/R.N.Morais \\
\hline Pon72 & Brazil, unknown State & CENAP/IBAMA \\
\hline Pon73 & Brazil, unknown State & CENAP/IBAMA \\
\hline Pon75 & Sinaloa State, Mexico & Brian Miller \\
\hline
\end{tabular}

•, samples typed only for microsatellites; ${ }^{*}$, samples typed only for mtDNA. 


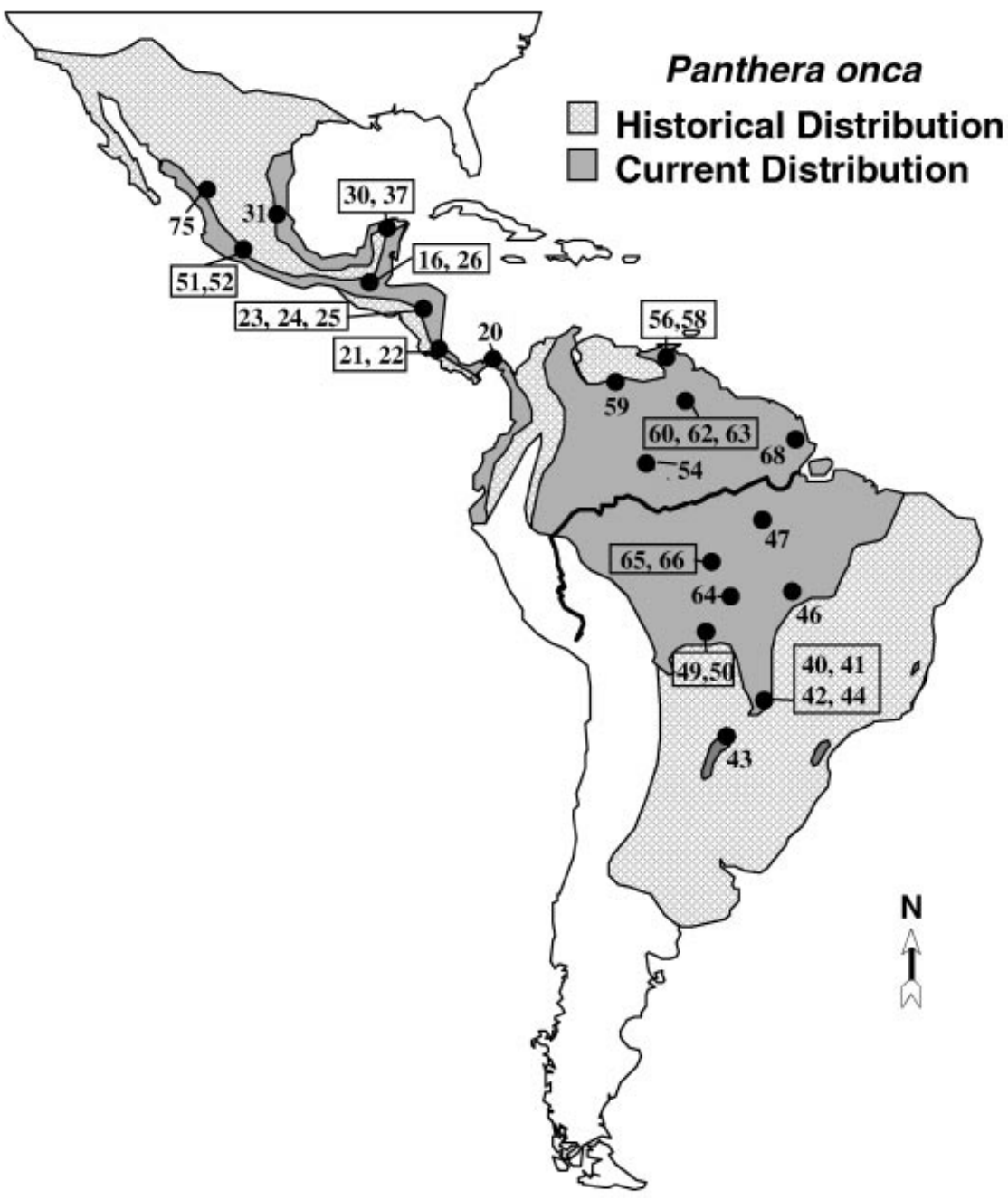

Fig. 1 Map showing historical and current geographical distribution of jaguars (modified from Oliveira 1994), approximate sample collection sites (black circles), and the location of the Amazon river. Numbers next to circles are sample identification labels of jaguar individuals (number after Pon in Table 1) from each area. Boxes indicate individuals from the same region. Only individuals with know regional origin are shown.

\section{Materials and methods}

\section{Sample collection and laboratory procedures}

Samples of 44 jaguar individuals were obtained from across most of the species' range (Table 1, Fig. 1). Whole blood preserved in a saturated salt solution (100 mM Tris, $100 \mathrm{~mm}$ EDTA, 2\% SDS) was collected from wild-caught individuals captured in field ecology projects; blood (separated into plasma, red blood cell and leucocyte phases) and skin biopsies were obtained from animals kept in captive breeding Institutions, most of which had known geographical origin; and skin fragments were collected from a museum pelt (sample Pon67). DNA extraction was performed using standard techniques: salt precipitation (Montgomery \& Sise 1990) was used for leucocyte pellets; phenol/chloroform (Sambrook et al. 1989) was used for whole blood and primary fibroblast cultures; and a silica-guanidium technique (Pääbo et al. 1988; Boom et al. 1990) was employed with the museum material.
The $5^{\prime}$ portion (including the First Hypervariable Segment, HVS-I) and the central conserved portion of the mtDNA control region (the structure of the felid mtDNA control region is described elsewhere: Lopez et al. 1996; Eizirik et al. 1998; J.-H. Kim et al. unpublished) were amplified by polymerase chain reaction (PCR) (Saiki et al. 1985) from genomic DNA. For the $5^{\prime}$ segment, human primers L15997 [modified to match the domestic cat reference sequence (Lopez et al. 1996)] and H16498 (Ward et al. 1991) were used, and for the central portion primers PAN-CCR-F (CTCAACTGTCCGAAAGTGCTT) and PANCCR-R (CCTGTGGAAGCAATAGGAATT) (J.-H. Kim et al. unpublished data) were employed. PCR reactions were performed using standard buffer conditions, $1.5 \mathrm{~mm}$ $\mathrm{MgCl}_{2}$, and 33-36 cycles of the following steps: $94^{\circ} \mathrm{C}$ for $45 \mathrm{~s}, 53{ }^{\circ} \mathrm{C}$ for $45 \mathrm{~s}$, and $72{ }^{\circ} \mathrm{C}$ for $1 \mathrm{~min}$, preceded by $3 \mathrm{~min}$ of initial denaturing, and followed by $10 \mathrm{~min}$ of final extension. PCR products were purified using CENTRICON100 (Amicon), and cycle-sequenced from both ends, using either ABI FS Dye Primer kits (in which case PCR primers 
had been engineered to contain M13 tails) or ABI Big Dye Terminator kits; resulting fragments were analysed in an ABI 373 A automated sequencer.

The $5^{\prime}$ portion of the mtDNA control region of felids contains a rather long tandem repetitive series, which leads to size variation and heteroplasmy in several species, including jaguars (Lopez et al. 1996; Eizirik et al. 1998; J.-H. Kim et al. unpublished data). Due to the difficulty in sequencing through this array, only one strand was sequenced on each flank of the repeats. Sequences were visually inspected and corrected using SEQUENCHER (Gene Codes Co.); sites or segments from which sequence could not be unambiguously scored after three attempts (independent PCR and sequencing reactions) were treated as missing information and excluded from the analysis. Similar care was taken with the central segment, although in this case both strands were available for analysis. As part of the mtDNA of cats of the Panthera genus is included in a nuclear transposition (Johnson et al. 1996), our data were compared to reference sequences obtained from isolated mitochondrial and nuclear extracts (which exhibited several nucleotide differences; J.-H. Kim et al. unpublished data) to ascertain that the haplotypes included in this study were indeed of mitochondrial origin.

Thirty-five microsatellite loci developed originally for the domestic cat (Menotti-Raymond et al. 1999) were amplified by PCR from jaguar genomic DNA using fluorescently labelled primers and the standard conditions described by Menotti-Raymond et al. (1999). The products were analysed in an ABI 310 automated sequencer. To assess amplification efficiency and yield, and to establish the size range for each microsatellite in the jaguar, an initial run was performed with three individuals for each locus separately. Twenty-nine loci (FCA005, FCA008, FCA026, FCA043, FCA075, FCA077, FCA90, FCA091, FCA094, FCA096, FCA097, FCA098, FCA105, FCA126, FCA139, FCA161, FCA193, FCA201, FCA211, FCA220, FCA224, FCA229, FCA247, FCA290, FCA293, FCA310, FCA441, FCA453 and FCA678 - Menotti-Raymond et al. 1999) were selected for use in this study. PCR reactions were carried out for each locus separately, and products from 3 to 5 loci were diluted and pooled together based on yield, size range and fluorescent dye, and subsequently analysed in an ABI 310 or ABI 377 automated sequencer. Resulting patterns were scored and analysed using the ABI computer programs GENESCAN 2.1 and GENOTYPER 2.1.

\section{Data analysis}

mtDNA control region sequences were aligned using CLUSTALX (Thompson et al. 1997) and visually checked. Initial sequence comparisons and measures of variability were performed using MEGA (Kumar et al. 1993). Transition/ transversion ratios and the $\alpha$ parameter of the gamma distribution of rate variation among sites (method of Yang \& Kumar 1996) were estimated using PAMP (included in the package PAML 2.0 - Yang 1999). Phylogenetic analyses of the identified sequences were performed using three approaches: (i) minimum evolution (ME) heuristic search as implemented in PAUP*4.0b2 (Swofford 1998), consisting of a distance-based (Tamura-Nei model with gamma correction) neighbour-joining (Saitou \& Nei 1987) tree followed by branch-swapping; (ii) maximum parsimony (MP) using PAUP*, with a heuristic search and random addition of taxa; and (iii) maximum likelihood (ML) using PAUP* and PUZZLE 4.0 (Strimmer \& Von Haeseler 1996), incorporating a gamma-corrected HKY (Hasegawa-KishinoYano) model with parameters estimated from the data set. Reliability of nodes defined by the phylogenetic trees was assessed using 100 bootstrap replications (Felsenstein 1985; Hillis \& Bull 1993) in the ME and MP analyses, and with the quartet puzzling method in the PUZZLE ML analysis. Minimum-spanning networks (Excoffier \& Smouse 1994) were constructed using MINSPNET (by L. Excoffier, http://anthropologie.unige.ch/LGB/software/win/) to depict phylogenetic, geographical, and potential ancestordescendent relationships among the identified sequences.

Measures of population genetic parameters such as gene diversity (the probability that two randomly chosen mtDNA sequences are different in the sample) and nucleotide diversity ( $\pi$ per nucleotide site, i.e. the probability that two randomly chosen homologous nucleotides are different in the sample) (Nei 1987) were estimated from the mtDNA data set using ARLEQUIN 1.1 (Schneider et al. 1997) and SENDBs (by N. Takezaki, methods described in Nei \& Jin 1989; Jin \& Nei 1990; http://www.bio.psu.edu/ People/Faculty/Nei/Lab/Programs.html. SENDBs was applied to derive measures of nucleotide diversity $(\pi)$ and their confidence intervals (using a bootstrap approach), which were used to date the origin of extant mtDNA lineages of jaguars. Dating of the origin of jaguar mtDNA haplotypes was also performed using the linearized tree method with the program LiNTREE (Takezaki et al. 1995), that incorporates two tests for the assumption of a molecular clock. Inference of past population expansion events was performed using mismatch distribution analyses (Rogers \& Harpending 1992) as implemented in ARLEQUIN, and lineages-through-time plots (Nee et al. 1994) as implemented in END-EPI (Rambaut et al. 1997). To assess the extent of differentiation among populations an Analysis of Molecular Variance (AMOVA) (Excoffier et al. 1992) was used to estimate $F_{\mathrm{ST}}$ values, whose statistical significance was tested using 10000 permutations as implemented in ARLEQUIN. We also applied the nested cladistic analysis proposed by Templeton et al. (1995) to make phylogeographic inferences with our mtDNA data set, using GEODIS 2.0 (Posada et al. 2000) and 10000 permutations to test the significance of alternative historical scenarios. 
Microsatellite data was analysed with MICROSAT (Minch 1997) for general estimates of diversity and calculation of several measures of genetic distance among individuals. Resulting distance matrices were used to construct neighbour-joining phylogenetic trees with the program NEIGHBOR [included in the package PHYLIP 3.5. (Felsenstein 1993)]. ARLEQUIN 1.1 was used to test for deviations from Hardy-Weinberg equilibrium (using an exact test based on the procedure described by Guo \& Thompson 1992) and to derive estimates of population subdivision (using $F_{\mathrm{ST}}$ and $R_{\mathrm{ST}}$ analogs; Weir \& Cockerham 1984; Slatkin 1995; Michalakis \& Excoffier 1996). The statistical significance of $F_{\mathrm{ST}}$ and $R_{\mathrm{ST}}$ values was tested using 10000 permutations as implemented in ARLEQUIN. To evaluate if there is support from microsatellite data to the inference of a population expansion in jaguars, the shape of the distribution of allele frequencies in each locus was inspected, and two statistical approaches were applied: (i) the $\mathrm{P}_{\mathrm{k}}$ distribution method of pairwise comparisons suggested by Shriver et al. (1997); and (ii) the interlocus $g$-test proposed by Reich \& Goldstein (1998) and Goldstein et al. (1999). The former is based on the shape of the distribution of pairwise differences in repeat number among all alleles of each locus, averaged across loci. We have performed a weighted average in which loci with the most complete data sets are proportionally more represented. The second approach ( $g$-test) compares the observed variance across loci of the variance in repeat scores to that expected in a population of constant size. We obtained the observed variance of the variance $\left(V_{1}\left[V_{r}\right]\right)$ empirically, based on the output of MICROSAT (using the total variance in repeat number per locus as $\mathrm{V}_{\mathrm{r}}$ ). The expected value under constant population size $\left(\mathrm{V}_{\mathrm{g}}\left[\mathrm{V}_{\mathrm{r}}\right]\right)$ was derived using the method suggested by Reich \& Goldstein (1998) and Goldstein et al. (1999), with the formula $\mathrm{V}_{\mathrm{g}}\left[\mathrm{V}_{\mathrm{r}}\right]=4 / 3 \mathrm{E}\left[\mathrm{V}_{\mathrm{r}}\right]^{2}+1 / 6 \mathrm{E}\left[\mathrm{V}_{\mathrm{r}}\right]$, in which the average variance across loci is substituted for $\mathrm{E}[\mathrm{Vr}]$.

\section{Results}

\section{mtDNA sequences}

mtDNA control region PCR products from 37 jaguar individuals (Table 1) were sequenced in three separate units. Fragment A was sequenced with primer L15997, and consisted of $183 \mathrm{bp}$ at the $5^{\prime}$ flank of the repetitive array. Fragment B was sequenced with primer H16498 and contained $\approx 240 \mathrm{bp}$ at the $3^{\prime}$ flank of the repetitive region, including the first ( $3^{\prime}$ side) 80 -bp repeat (all repeats but the first were excluded from the data set). Fragment $C$ spanned the central conserved portion of the mtDNA control region, containing $\approx 390 \mathrm{bp}$ sequenced for both strands using primers PAN-CCR-F and PAN-CCR-R, and overlapping with $\approx 100 \mathrm{bp}$ of fragment B. Fragment A sequences were concatenated with the contigs generated from fragments B and C, producing a complete aligned data set of $715 \mathrm{bp}$ [positions 16315-00218 in the domestic cat reference sequence (Lopez et al. 1996)]. Sequences of the same control region segment from a lion (Panthera leo) and a leopard (P. pardus) were used as outgroups (J.-H. Kim et al. unpublished data). A 66-bp segment of the leopard sequence on the $5^{\prime}$ flank of the repetitive array could not be aligned with the other sequences, and was removed from the analyses. The alignment of the jaguar sequences (GenBank accession nos AF244814AF244887) is available at http://lgd.nci.nih.gov (as supplementary information linked to this paper).

Sequences from the 37 jaguar individuals comprised 22 different haplotypes defined by 33 variable sites (Table 2). The estimated transition:transversion ratios varied from 1:6 to 1:16 depending on the inclusion of outgroup sequences. Among-site rate variation was high ( $\alpha=0.0023-0.3945$ depending on inclusion of outgroups).

Moderate to high levels of gene diversity and considerably low nucleotide diversity were observed among jaguar individuals (Table 3). Sequence identity was observed only among individuals originating from the same or adjacent geographical regions, with the exception of one haplotype which was widespread in the northern portion of the range, from Venezuela to Mexico (Pon21, 25, 31, 51, 58, 59, 60, and 75, Figs 2 and 3). Phylogenetic analyses of jaguar mtDNA sequences did not strongly support the existence of any major phylogeographic partitions (Fig. 2). The overall pattern approximated a star-phylogeny, with generally short branches and little robust structure, a pattern reminiscent of a relatively recent population expansion (Lavery et al. 1996; Avise 2000). The only phylogeographic partition which received consistent support in all analyses was the grouping of southern South American sequences (all the sequences from Brazil and Paraguay, one sequence probably from Peru, and most from Bolivia) in two monophyletic groups (Fig. 2). The rooting of the trees using other Panthera genus species as outgroups suggested that the northern South American/Central American sequences were more basal than the two southern South American clusters.

The minimum-spanning network (Fig. 3) of the jaguar mtDNA sequences provided additional support for the two southern South American clusters, and for their independent connection to a more basal northern sequence. This diagram is also indicative of a relatively recent population expansion in the group of northern sequences, in which several localized lineages are connected by short branches to the most common, potentially ancestral, widespread haplotype. With the exception of the basal Pon37, all Mexican individuals either carried the widespread 'Pon 21 ' haplotype or a sequence which had been recently derived (being one step away) from it. 
Table 2 Mitochondrial DNA control region haplotypes identified for jaguars (Panthera onca) in this study. Nucleotide positions showing variation among jaguar haplotypes are depicted; numbers (vertical) refer to the aligned site in our 715 bp data set [which corresponds to positions 16315-00218 in the domestic cat reference sequence (Lopez et al. 1996)]. Nucleotides present at these sites in the outgroups (Panthera leo and P. pardus) are shown in the bottom. The geographical origin of jaguar individuals bearing each haplotype is also indicated

\begin{tabular}{|c|c|c|c|c|c|}
\hline \multirow[b]{4}{*}{ Individuals } & \multicolumn{4}{|c|}{ Nucleotide positions } & \multirow[b]{4}{*}{ Geographic origin } \\
\hline & 111112 & 2222222334 & 4444445666 & 677 & \\
\hline & 2356335783 & 4445689280 & 0135783137 & 801 & \\
\hline & 4231497368 & 1582601077 & 9182658185 & 300 & \\
\hline Pon $21,25,31,51,58,59,60,75$ & ATTTAGCTCA & AAACTCTGTA & TATATGGTGA & TAT & V, CR, Nic, Mex \\
\hline Pon16, 26, 30 & $\ldots \ldots$. . & $\ldots \ldots \ldots$ & $\ldots \ldots \ldots$ & $\ldots$ & Guat, Mexico \\
\hline Pon52 & $\ldots \ldots \ldots$ & $\ldots \ldots \ldots$ & $\ldots \ldots \ldots$ &. $\mathrm{G}$. & Mexico \\
\hline Pon37 & $\ldots \ldots \ldots$ & $\ldots \ldots ? \ldots$ & ?G..A..A. & $\ldots$ & Mexico \\
\hline Pon20 & $\ldots \ldots \ldots$ & $\ldots \ldots \ldots G$ & ...А.А. & $\ldots$ & Panama \\
\hline Pon22, 24 & $\ldots$.... & $\ldots \ldots \ldots$. & $\ldots \ldots$ А. & $\ldots$ & $\mathrm{CR}, \mathrm{Nic}$ \\
\hline Pon23 & $\ldots$... & G?TG?...C. & $\ldots \ldots$ A. & $\ldots$ & Nicaragua \\
\hline Pon56 & $\ldots \ldots \mathrm{T}$ & $\ldots \ldots \ldots$ & $\ldots \ldots \ldots$ & C. . & Venezuela \\
\hline Pon61 & $\ldots \ldots \ldots$ & $\ldots \ldots$ А. & $\ldots \ldots \ldots G$ & $\ldots$ & Venezuela \\
\hline Pon63 &. $\mathrm{CC} ? \ldots \mathrm{T}$ & ....т . . & ..G...A. & $\ldots$ & Venezuela \\
\hline Pon68 & $\ldots \ldots \ldots$ & $\ldots \ldots \ldots$ & $\ldots \ldots \ldots G$ & $\ldots$ & Fr. Guiana \\
\hline Pon29, 41, 42, 44 & G..G.T.T. &.$G \ldots \ldots$ & С?...А. .А. & $\ldots$ & Brazil \\
\hline Pon 40,46 & G..G.T.T. &.$G \ldots \ldots$ & ....А. А. & $\ldots$ & Brazil \\
\hline Pon71 & G..CG.T.. & .G.?C.... & ..G...A. & $\ldots$ & Brazil \\
\hline Pon73 & G..G.T.T. &.$G \ldots \ldots \ldots$ & ..G...A. & $\ldots$ & Brazil \\
\hline Pon72 & ...G... & ....... & ??...А. .А. & $\ldots$ & Brazil \\
\hline Pon 28,47 & $\ldots$...... & ....... & ..GC.A..G & .G. & Peru (P), Bra \\
\hline Pon43 & ...G.... & ...... & . CGC.A..G & $\ldots$ & Brazil \\
\hline Pon64 & $\ldots$...... & $\ldots \ldots \ldots$ & ..GC.A..G & .GC & Bolivia \\
\hline Pon65 & $\ldots ? \ldots \ldots$ & $\ldots \ldots \ldots$ & ....... & $\ldots$ & Bolivia \\
\hline Pon66 & $\ldots$. G.... & .....А. & .G.GC.A..G &.$G$. & Bolivia \\
\hline Pon49 & ?...G.... & ....... & ...G?.A..G & $\ldots$ & Paraguay \\
\hline Ple181 &. .С... & $\ldots$. C-CA. & ..G.A.... & $\ldots$ & \\
\hline Рpa21 & G.C..---- & $\ldots \ldots \ldots$ & .G.G.A.CA. & $\ldots$ & \\
\hline
\end{tabular}

Abbreviations: V, Venezuela; CR, Costa Rica; Nic, Nicaragua; Mex, Mexico; Guat, Guatemala; Fr. Guiana, French Guiana, Bra, Brazil; (P), Probable origin.

Table 3 Measures of mitochondrial DNA diversity observed in the two major phylogeographic groups of Panthera onca identified in this study, Southern and Northern (see text for definition), as well as separate estimates for Central America (C.A.) and Northern South America (N.S.A.), which are included in the Northern group. Estimates for the two separate subgroups in Central America (fourpopulation scenario) are not provided due the small sample size available for each of them

\begin{tabular}{|c|c|c|c|c|c|c|}
\hline & $n$ & $\begin{array}{l}\text { No. of } \\
\text { haplotypes }\end{array}$ & $\begin{array}{l}\text { No. of bp } \\
\text { differences }\end{array}$ & $\begin{array}{l}\text { \% Pairwise } \\
\text { divergence* }\end{array}$ & Gene diversity $†$ & $\begin{array}{l}\text { Nucleotide } \\
\text { diversity }(\pi)^{*}+\end{array}$ \\
\hline Total & 37 & 22 & $1-15$ & $0.14-2.35$ & $0.9399 \pm 0.0262$ & $0.00771 \pm 0.00010$ \\
\hline Southern & 16 & 11 & $1-13$ & $0.14-1.94$ & $0.9333 \pm 0.0477$ & $0.00815 \pm 0.00000$ \\
\hline Northern & 21 & 11 & $1-12$ & $0.14-1.87$ & $0.8476 \pm 0.0697$ & $0.00448 \pm 0.00015$ \\
\hline C.A. & 14 & 7 & $1-8$ & $0.14-1.25$ & $0.8462 \pm 0.0742$ & $0.00411 \pm 0.00024$ \\
\hline N.S.A. & 7 & 5 & $1-9$ & $0.14-1.29$ & $0.8571 \pm 0.1371$ & $0.00475 \pm 0.00000$ \\
\hline
\end{tabular}

*Estimated using Kimura 2-parameter distances (Kimura 1980).

tSites with any missing information were completely excluded. 

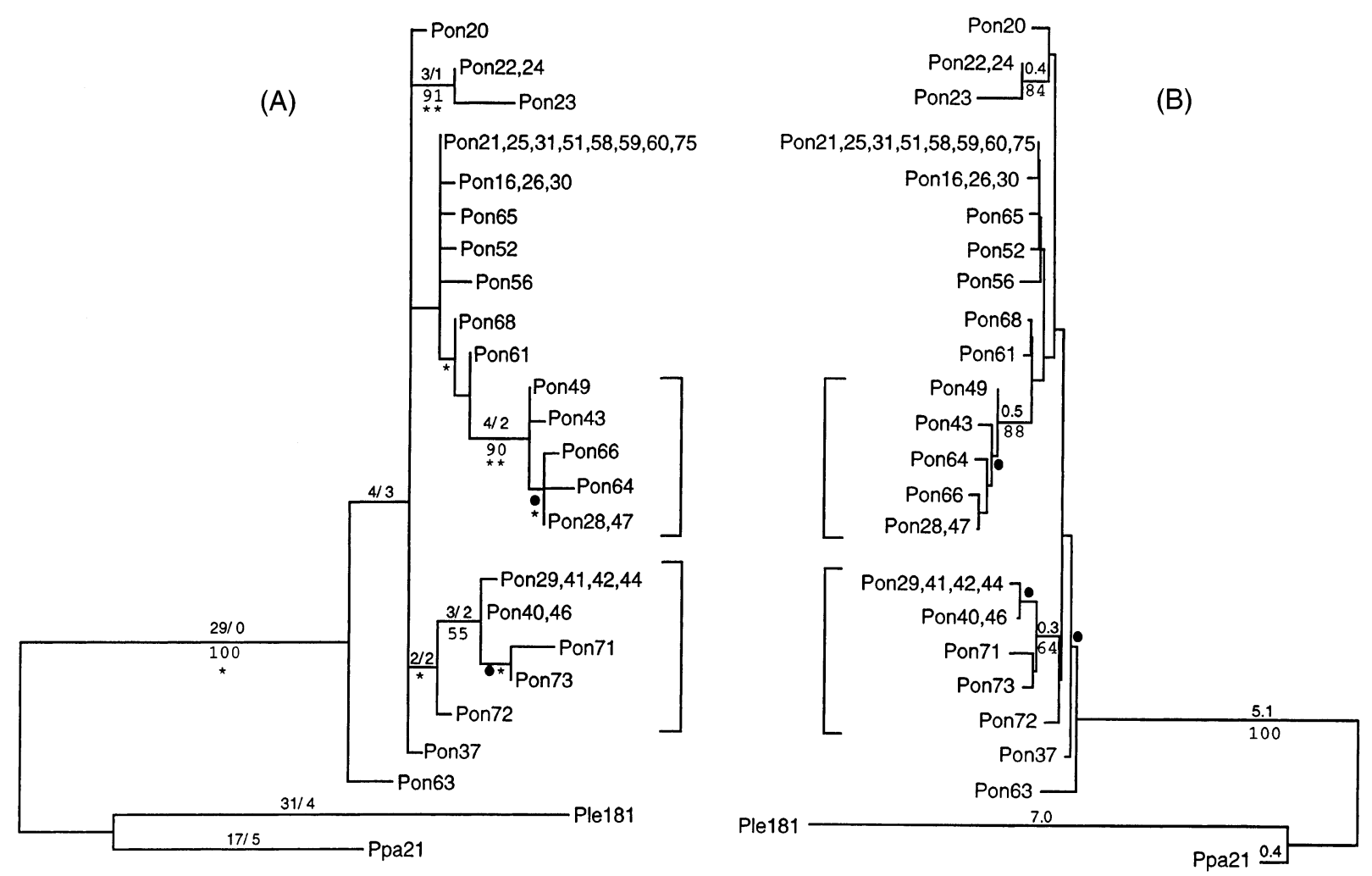

Fig. 2 Phylogenetic relationships among the jaguar mitochondrial DNA (mtDNA) sequences identified in this study, based on 715 bp of the mtDNA control region. Labels are individual identification numbers. The two southern clades are identified by brackets. (A) Maximum parsimony tree constructed with PAUP* using a heuristic search with 10 replicates of random taxon addition and the accelerated transformation option for character-state optimization; shown is the strict consensus of eight trees (length $=122$, CI $=0.818$ ). Values above selected branches indicate number of steps/number of homoplasies; values below branches represent support from 100 bootstrap replications (heuristic searches with random taxon-addition, constrained to generate a maximum of 1000 trees); black circles indicate other branches with bootstrap support $\geq 50 \%$. Asterisks below branches indicate support from 1000 quartet puzzling steps in the maximum likelihood analysis with PUZZLE $\left(^{*}=\right.$ support for branch $>50 \%$; ${ }^{* *}=$ support for branch $>80 \%$ ). (B) Minimum evolution tree, constructed with PAUP* using Tamura-Nei distances corrected for the gamma distribution of rate variation among sites $(\alpha=0.39)$ and the neighbour-joining algorithm followed by a branch-swapping procedure. Values above selected branches indicate branch lengths as percentages; values below branches represent support from 100 bootstrap replications (heuristic searches constrained to a maximum of 500 trees); black circles indicate other branches with bootstrap support $\geq 50 \%$.

The mismatch distribution of jaguar mtDNA haplotypes (Fig. 4A) was approximately unimodal and wave-like, which is compatible with a population bottleneck and/or expansion in the recent past (Rogers \& Harpending 1992). The lineages-through-time plots (Fig. 4B) produced a clearly convex-shaped curve, particularly when restricted to the earliest haplotype coalescence events, which seems to be also consistent with an initial period of exponential population growth (Nee et al. 1994).

The measures of nucleotide diversity $(\pi)$ and divergence $\left(d_{x y}\right)($ Nei 1987) were used to estimate a coalescence date for jaguar mtDNA sequences (derived as the average pairwise coalescent time of the sampled jaguar haplotypes) and its $95 \%$ confidence interval (CI: $\pm 2 \mathrm{SE}$ ). For this analysis, all sites which contained gaps or missing information in any haplotype, including outgroups, were excluded, and all estimates were derived from the remaining 556 nucleotides. This minimized the effects of saturation in interspecific comparisons as some of the most variable sites were excluded. To estimate the substitution rate of this mtDNA segment, the average distance $\left(\mathrm{d}_{\mathrm{xy}}\right)$ between the jaguar sequences and the outgroups (lion and leopard) was computed $\left(\mathrm{d}_{\mathrm{xy}}=0.07499\right.$ \pm 0.002839 ), based on a Kimura 2-parameter model of nucleotide substitution, corrected with a gamma distribution of rate variation among sites, with an $\alpha$ (shape) parameter derived specifically for this data set $(\alpha=0.13)$. The standard equation $\mathrm{d}_{\mathrm{xy}}=2 \mu \mathrm{T}$ (where $\mu$ is the substitution rate and T is time; Nei 1987) and a conservative fossil record calibration (3 Ma) (Turner \& Antón 1997) for the separation of jaguars from lions/leopards produced a substitution rate of 0.012498 per site per million years (Myr), or approximately $1.2 \% / \mathrm{Myr}$. Applying the same equation and this substitution rate to the overall 


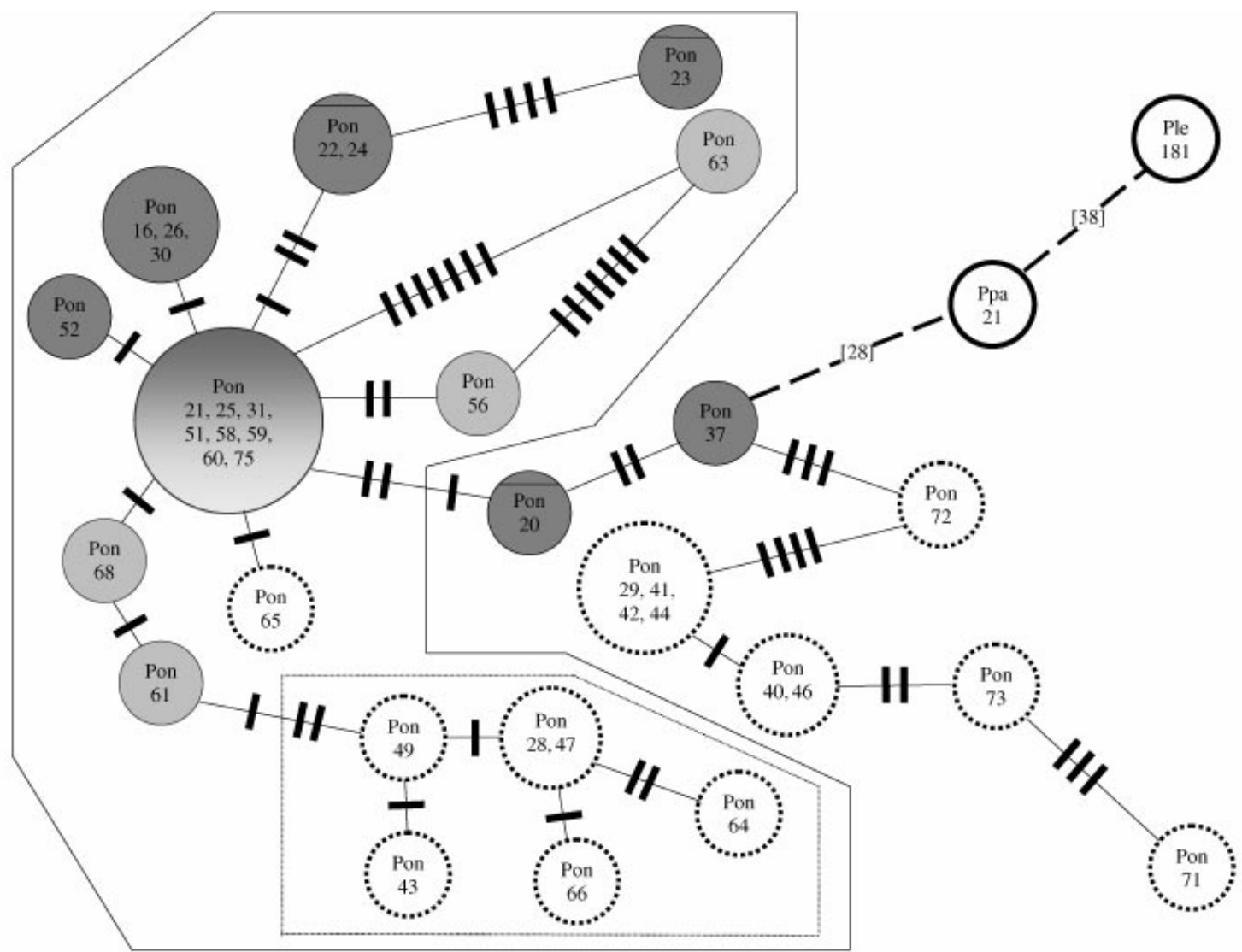

Fig. 3 Minimum-spanning network depicting phylogenetic and geographical relationships among jaguar mitochondrial DNA (mtDNA) haplotypes (circles) based on sequences of $715 \mathrm{bp}$ of the control region. The area of the circle is roughly proportional to the haplotype frequency, and the length of connecting lines is roughly proportional to the corrected distance (Tamura-Nei gamma, $\alpha=0.39$ ) between haplotypes. Use of the raw number of nucleotide differences among haplotypes produced a concordant result. Labels inside each circle indicate individual jaguars bearing each haplotype. Dark grey circles (with no upper horizontal line) are haplotypes occurring only in Mexico and Guatemala; dark grey circles with an upper horizontal line occurred only in southern Central America (see text for definition); light grey circles are those found in northern South America (Venezuela and French Guiana); the large graded grey circle is a widespread haplotype found from Mexico to Venezuela; white dotted circles are haplotypes found only in southern South America (Brazil, Bolivia, Paraguay and potentially Peru). Bars placed on connecting lines indicate the exact number of nucleotide differences between haplotypes. White circles bordered by heavy lines are outgroups; the number of nucleotide differences in their connecting lines (not drawn to scale) is indicated in brackets. Polygons demarcate selected clades for which significant results were observed in the nested cladistic analyses (no outgroup was used in this approach). The dotted line internal polygon indicates a geographically restricted 3-step clade that showed a significantly small $(P<0.001)$ within-clade distance, and a significantly large $(P=0.0001)$ nested-clade distance $($ see Templeton 1998 for definition of statistics). The solid line polygon demarcates a 4-step clade that showed a significant value $(P<0.0001)$ for nonrandom geographical distribution of subclades in the exact contingency test implemented in GEODIS, and a significantly large $(P<0.0001)$ interior - tip distance. This 4 -step clade also showed significantly small within-clade and nested-clade distances $(P<0.05)$ when compared to the whole network.

jaguar nucleotide diversity in this segment $(\pi=0.00699 \pm$ $0.000733)$ produced an estimated age of 279645 years $(95 \%$ $\mathrm{CI}=220$ 990-338 290 years) for the coalescence of jaguar mtDNA haplotypes. If the $95 \% \mathrm{CI}$ of $\mathrm{d}_{\mathrm{xy}}$ is also considered when estimating the substitution rate (Bonatto \& Salzano 1997), an upper bound of 366000 years ago is obtained. Using the $95 \%$ CI for both $\pi$ and the substitution rate, and a more recent calibration date for the separation of jaguars from lions/leopards (2 Myr), provided an overall lower bound of 136956 years ago for the coalescence of jaguar mtDNA sequences. The molecular clock tests implemented in LINTREE showed that the set of jaguar sequences used for the analysis above did not depart significantly from rate constancy $(P>0.05)$, but indicated that three haplotypes exhibited a marginally significant reduction in rate. Removal of haplotypes that failed either of the rate-constancy tests in separate analyses with each of the two outgroups produced a range of estimates of 407 905-510 401 years ago for the basal divergence of jaguar mtDNA lineages (applying the substitution rate derived above with the $3 \mathrm{Myr}$ calibration). The $95 \% \mathrm{CI}$ of these estimates ranged from 165627 to 830293 years ago. 
(A)

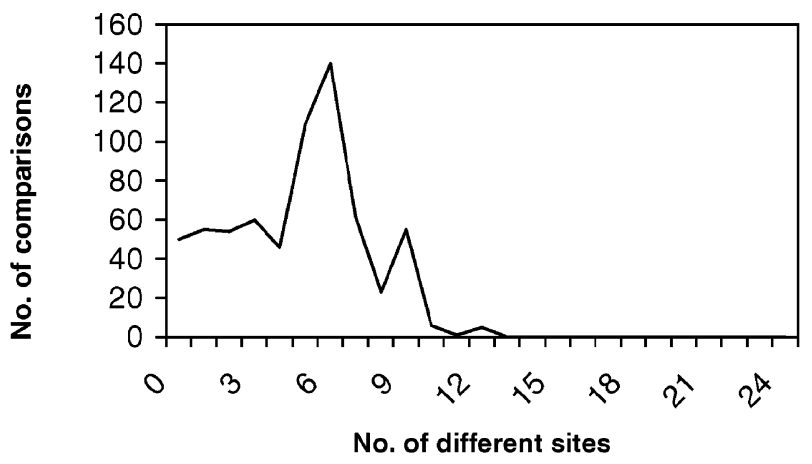

(B)

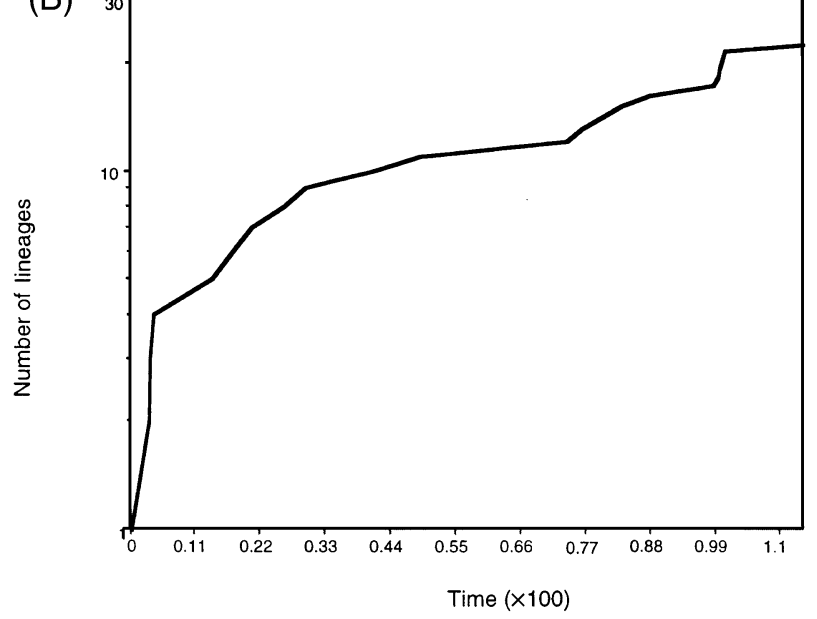

Fig. 4 (A) Mismatch distribution analysis of jaguar mitochondrial DNA (mtDNA) control region sequences. (B) Lineages-through-time plot based on a phylogeny of jaguar mtDNA haplotypes constructed from Kimura 2-parameter distances. The number of lineages is shown as a semi-logarithmic transform.

To investigate the extent of population differentiation in jaguars based on mtDNA haplotypes, we compared different scenarios of geographical subdivision. In the first one, individuals were divided into two broad geographical groups, which had been suggested by the topology of the mtDNA phylogeny. One group encompassed the northern part of the jaguar distribution (Northern group: Mexico, Central America, Venezuela and French Guiana), and the other contained the southern part (Southern group: Brazil, Bolivia, Paraguay, and two samples probably from Peru and southern South America, respectively). This subdivision scheme implied that the Southern group contained all sequences present in the two independent 'southern clades' (Figs 2 and 3), as well as the haplotype Pon65. In the second hypothesized scenario of geographical subdivision, we divided jaguar haplotypes into three groups. The Southern group was maintained, but the Northern group was
Table 4 Measures of geographical population differentiation in Panthera onca, based on an Analysis of Molecular Variance approach with mitochondrial DNA (mtDNA) and microsatellite data

\begin{tabular}{|c|c|c|c|}
\hline Subdivisiont & $\begin{array}{l}\operatorname{mtDNA} \\
F_{\mathrm{ST}} \ddagger\end{array}$ & $\begin{array}{l}\text { Microsatellites } \\
F_{\mathrm{ST}} \S\end{array}$ & $R_{\mathrm{ST}} \mathbb{I}$ \\
\hline 2 populations & $0.342^{* *}$ & $0.045^{* *}$ & $0.154^{* *}$ \\
\hline 3 populations & $0.295^{* *}$ & $0.065^{* *}$ & $0.171^{* *}$ \\
\hline S. vs. N.S.A. & $0.261^{*}$ & $0.020^{*}$ & $0.067^{*}$ \\
\hline S. vs. C.A. & $0.354^{* *}$ & $0.083^{* *}$ & $0.237^{* *}$ \\
\hline N.S.A. vs. C.A. & 0.079 & $0.077^{* *}$ & $0.140^{* *}$ \\
\hline 4 populations & $0.300^{* *}$ & $0.063^{* *}$ & $0.183^{* *}$ \\
\hline S. vs. N.S.A. & $0.261^{*}$ & $0.020^{*}$ & $0.067^{*}$ \\
\hline S. vs. S.C.A. & $0.333^{*}$ & $0.085^{* *}$ & $0.223^{* *}$ \\
\hline S. vs. $M+G$ & $0.358^{* *}$ & $0.084^{* *}$ & $0.266^{* *}$ \\
\hline N.S.A. vs. S.C.A. & $0.185^{*}$ & $0.075^{*}$ & $0.131^{*}$ \\
\hline N.S.A. vs. $M+G$ & 0.082 & $0.083^{* *}$ & $0.185^{* *}$ \\
\hline S.C.A. vs. $M+G$ & $0.257^{*}$ & 0.025 & $0.140^{*}$ \\
\hline
\end{tabular}

*significant $(P<0.05)$; ${ }^{* *}$ significant $(P<0.001)$.

tPopulation subdivision scenarios are described in the text; the two-population scheme depicts south (S) vs. north (N)

comparisons; the three-population scheme retains the southern group (S), and divides the northern group into northern South America (N.S.A.) and Central America (C.A.); the fourpopulation scheme further divides C.A. into separate S.C.A. (southern Central America: Panama, Costa Rica, Nicaragua) and $\mathrm{M}+\mathrm{G}$ (Mexico + Guatemala).

†Calculated using Tamura-Nei distances (Tamura \& Nei 1993). §Calculated with the $F_{\mathrm{ST}}$ option (number of different alleles) in ARLEQUIN.

IICalculated with the $R_{\mathrm{ST}}$ option (sum of squared size difference) in ARLEQUIN (Michalakis \& Excoffier 1996).

separated into Central America (including Mexico) and northern South America, aiming to test the significance of the Darien straits in Panama as a historical barrier to gene flow in this species. Finally, a third scenario was tested in which Central America was subdivided into two separate groups (Mexico + Guatemala; Nicaragua + Costa Rica + Panama), producing a total of four groups. This pattern of geographical subdivision in Central America has been observed in a previous study of Neotropical felids (Eizirik et al. 1998). Other possible scenarios of population subdivision were considered, but could not be thoroughly assessed at the present time due to limitations in sample size for particular areas and lack of precision in the geographical origin of most individuals.

Using the two-group scheme, the estimated $F_{\mathrm{ST}}$ value was $0.342(P<0.0001)$ (Table 4). Using the three- and four-group scenarios, the $F_{\mathrm{ST}}$ estimates decreased to 0.295 and 0.300 , respectively $\left(P<0.0001\right.$ for both). Pairwise $F_{\mathrm{ST}}$ estimates between the southern group (south of the Amazon River) and all northern groups remained significant, but the $F_{\mathrm{ST}}$ between northern South America and part of Central America was not $(P>0.05)$ (see Table 4$)$. This is likely due 
Table 5 Measures of diversity at 29 microsatellite loci in the two major phylogeographic groups of Panthera onca identified in this study, Southern and Northern (see text for definition), as well as separate estimates for Central America (C.A.) and Northern South America (N.S.A.), which are included in the Northern group. Estimates for the two separate subgroups in Central America (four-population scenario) are not provided due the small sample size available for each of them

\begin{tabular}{|c|c|c|c|c|c|c|}
\hline & $n$ & $\begin{array}{l}\text { Average } \\
\text { heterozygosity }\end{array}$ & $\begin{array}{l}\text { Average } \\
\text { No. of alleles }\end{array}$ & $\begin{array}{l}\text { Average } \\
\text { variance }\end{array}$ & $\begin{array}{l}\text { Average allele } \\
\text { size range }\end{array}$ & $\begin{array}{l}\text { No. of private } \\
\text { alleles }\end{array}$ \\
\hline Total & 42 & 0.739 & 8.310 & 6.946 & 9.862 & - \\
\hline Southern & 17 & 0.724 & 6.655 & 6.520 & 8.034 & 43 \\
\hline Northern & 25 & 0.695 & 6.828 & 6.352 & 8.690 & 48 \\
\hline C.A. & 16 & 0.622 & 5.172 & 6.118 & 7.310 & 22 \\
\hline N.S.A. & 9 & 0.690 & 5.138 & 6.514 & 6.931 & 12 \\
\hline
\end{tabular}

to the predominance in Mexico and Guatemala of the widespread 'Pon21' haplotype and others closely related to it. These mtDNA results support the recognition of two main phylogeographic groups of jaguars, Southern and Northern (probably separated by the Amazon River), but also suggest a pattern of regional subdivision in the northern part of the range. $F_{\mathrm{ST}}$ estimates based on gammacorrected distances with extremely low values of $\alpha$ (not shown) also supported a south-north division of jaguar haplotypes.

The nested cladistic analysis proposed by Templeton et al. (1995) was performed on the basis of the haplotype tree shown in Fig. 3, and considering four broad geographical areas (four-population scenario described above) as operational units. Significant association of clades and geography was observed only at the 3-step and 4-step levels of the nested analysis. In one of the two 4-step clades (demarcated within a solid-line polygon in Fig. 3) the exact contingency test significantly rejected $(P<0.0001)$ the null hypothesis of no geographical association. In this clade, significantly small $(P<0.05)$ within-clade distances $\left(D_{c}\right)$ were detected for all nested tip 3-step subclades, and a significantly large $(P<0.0001)$ interior - tip $\mathrm{D}_{\mathrm{c}}$ was also observed. One of these nested 3-step subclades (shown as a dotted-line polygon in Fig. 3) exhibited a significant reversal of small within-clade distance vs. large nestedclade distances $\left(\mathrm{D}_{\mathrm{n}}\right)$, which led to the inference of longdistance colonization (from north to south) as the cause for the observed pattern (see Templeton 1998 for a review on the interpretation of this analysis). When the whole tree was examined (a dichotomous comparison of the indicated 4-step clade vs. the remaining jaguar haplotypes), the null hypothesis was again rejected $(P<0.05)$ in the exact contingency test, significantly small $(P<0.05)$ $D_{c}$ and $D_{n}$ were detected for the demarcated clade, and a significantly large $D_{n}$ was detected for the second major clade. These results suggest a historical scenario of restricted gene flow with isolation by distance over broad geographical areas.

\section{Microsatellite variation}

Allele size variation at 29 microsatellite loci was recorded for 42 jaguars (Table 1), as well as for two lions and two leopards to be used as outgroups. Twenty-seven of these loci were dinucleotide repeats, and two (FCA441 and FCA453) were tetranucleotide repeats (Menotti-Raymond et al. 1999). One of the dinucleotide loci (FCA293) was monomorphic in our jaguar sample. The genotypes used in the present analyses are available at http:// lgd.nci.nih.gov (as supplementary information linked to this paper). All loci, except FCA098, have been mapped in the domestic cat (Menotti-Raymond et al. 1999). Twentyfour were at least $15 \mathrm{~cm}$ apart implying independent allele assortment; two pairs of loci [FCA075, FCA096] and [FCA161, FCA224] were linked at distances of $9.0 \mathrm{~cm}$ and $4.0 \mathrm{~cm}$, respectively. Deviations from Hardy-Weinberg (HW) equilibrium in the microsatellite loci were tested separately for three geographical populations: southern South America, northern South America, and Central America (see below). Five loci were out of HW equilibrium in the former, six in the second population, and nine in the latter $(\alpha=0.05)$. After applying the sequential Bonferroni correction (Rice 1989), only one locus in the southern group and another in Central America remained significantly out of HW equilibrium. Comparative analyses excluding the 14 loci that were out of equilibrium in any population (uncorrected assessment) indicated no significant change in the results relative to our complete data set, other than slight reductions in estimates of genetic diversity and geographical differentiation. We have, therefore, used our complete data set of 29 loci throughout the analyses presented here, except where otherwise stated.

Overall levels of genetic diversity were moderate to high, with an average expected heterozygosity of 0.739 (Table 5). The phylogenetic analysis of microsatellite variation across individuals showed no evidence of strong geographical structure, nor provided reliable support for any major partition, but suggested a clustering of individuals from 


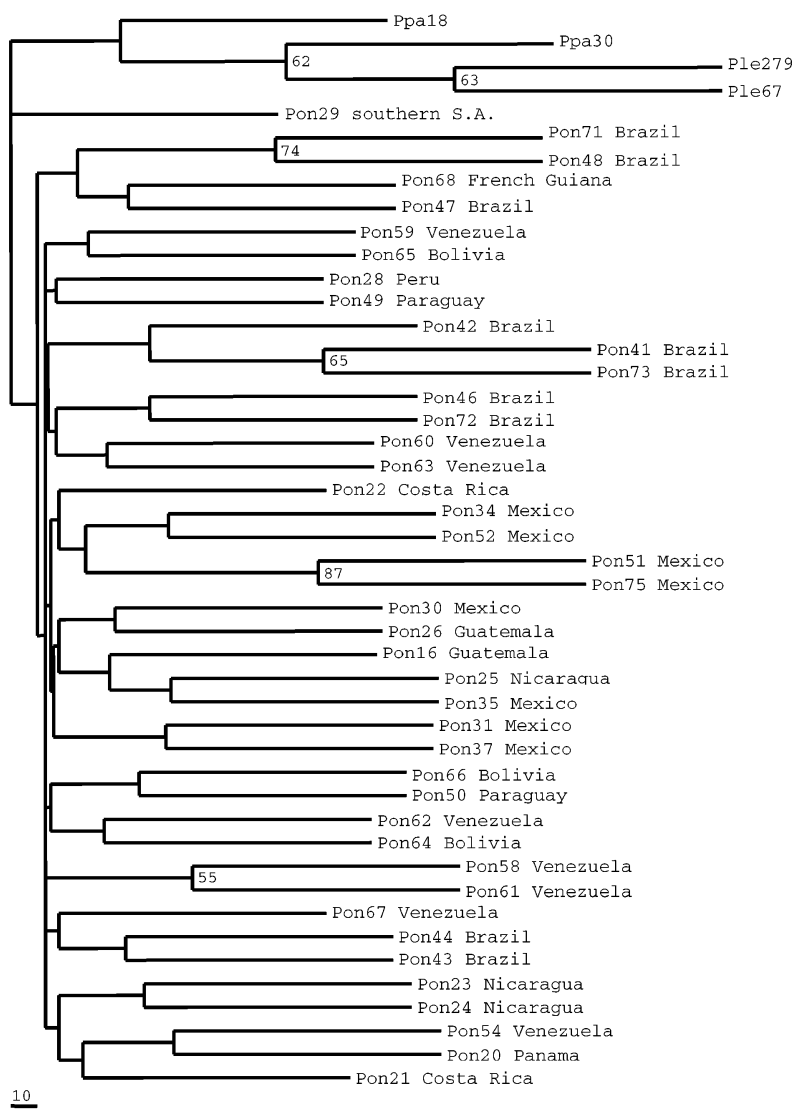

Fig. 5 Phylogenetic relationships among jaguar individuals based on variation at 29 microsatellite loci. The tree was constructed using the Neighbour-Joining algorithm based on the Proportion of Shared Alleles distance measure (Bowcock et al. 1994), using the option (1-ps) in місRоsAT. Values above branches are percent support in 100 bootstrap replications (only values above $50 \%$ are shown). The geographical origin of individuals is indicated next to each sample label.

nearby regions (Fig. 5). Phylogenetic trees generated using different distance measures (Dps, Dkf - Bowcock et al. 1994) led to very similar conclusions.

The shape of the distribution of allele sizes varied across microsatellite loci. Of the 28 variable loci, 13 had clearly unimodal distributions, which according to Reich \& Goldstein (1998) can be expected for populations that underwent a demographic expansion in the past. Five other loci had a distribution that was approximately unimodal, while 10 loci clearly departed from this pattern. The two statistical approaches to estimate demographic history with microsatellite data were performed for the jaguar sample as a whole, using only the 26 polymorphic dinucleotide loci, and provided results that are also compatible with a population expansion. The $\mathrm{P}_{\mathrm{k}}$ method of Shriver et al. (1997) produced an average distribution of pairwise differences in repeat number which showed the highest point at a plateau between values 0 and 1 (Fig. 6). The g-test of Reich \& Goldstein (1998) produced a value of 0.592 for

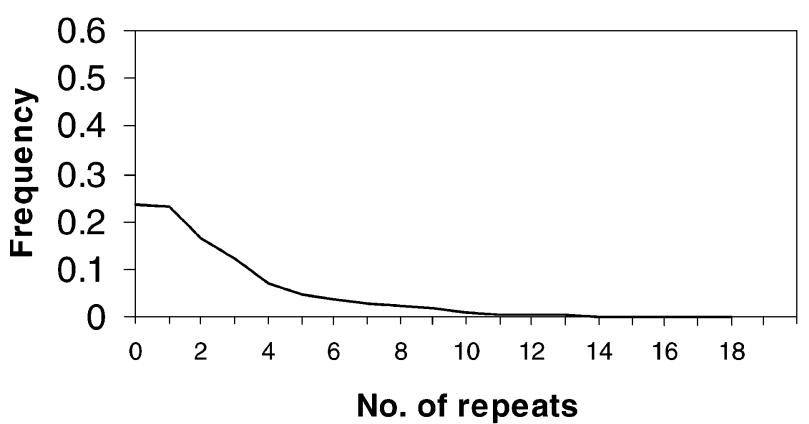

Fig. $6 \mathrm{P}_{\mathrm{k}}$ distribution of differences in repeat number among alleles at a microsatellite locus, averaged in a weighted fashion across 26 dinucleotide loci in our complete Panthera onca data set.

the ratio $\mathrm{V}_{\mathrm{l}}\left[\mathrm{V}_{\mathrm{r}}\right] / \mathrm{V}_{\mathrm{g}}\left[\mathrm{V}_{\mathrm{r}}\right]$. Inclusion of only 24 unlinked loci in the analysis produced a similar result.

As with the mtDNA data, the statistical analysis of population differentiation was performed for different hypothesized geographical partitions. Measures of differentiation $\left(F_{\mathrm{ST}}\right.$ and $\mathrm{R}_{\mathrm{ST}}$ analogs) were significant $(P<0.05)$ in all comparisons except for the subdivision of Central America into two separate groups (four-population scenario) in the $F_{\mathrm{ST}}$ estimate (Table 4$) . R_{\mathrm{ST}}$ estimates, which correct for allele size variation, indicated higher levels of differentiation than $F_{\mathrm{ST}}$ estimates, which only consider the number of different alleles. However, both of these methods produced higher overall levels of differentiation with three geographical groups compared with two, and the $R_{\mathrm{ST}}$ estimate was maximized when four separate groups were hypothesized (see Table 4). These microsatellite results support the recognition of at least three or four incompletely isolated phylogeographic groups in jaguars, but may also reflect, at least in part, a pattern of isolation by distance over most of the species' range. Measures of microsatellite diversity were similar in different geographical regions (Table 5).

\section{Discussion}

\section{Population history}

Observed levels of genetic diversity in jaguars were low to moderate for the mtDNA data, and medium to high in terms of microsatellite variability. The mtDNA diversity estimates presented here cannot be directly compared to other felids because data on the equivalent segment is unavailable from other species. However, if only the 453-bp long segment used by Eizirik et al. (1998) in two smaller Neotropical cats, ocelots (Leopardus pardalis) and margays (L. wiedii), is considered, jaguars show a threeto tenfold reduction in several measures of diversity (e.g. per cent sequence divergence among haplotypes, nucleotide diversity) relative to these two species (Eizirik 
et al. 1998; this study). By contrast, the microsatellite variation observed in jaguars is comparable to, or higher than, that of other felid species analysed so far, including the domestic cat, for which these markers were originally designed (Driscoll 1998; Johnson et al. 1999; MenottiRaymond et al. 1999; Culver et al. 2000). Taken together, these results suggest a younger age for jaguars as a species compared to other Neotropical felids, particularly ocelots and margays (Eizirik et al. 1998; Johnson et al. 1998, 1999).

The pattern observed in the jaguar intraspecific mtDNA phylogeny is consistent with a fairly recent population expansion, with little divergence among haplotypes (Table 3, Fig. 2) and insufficient time and/or isolation to generate regional differentiation. A similar inference can be made from the microsatellite phylogeny (Fig. 5). More individual variation is observed, but there is still no strong support for major geographical structure, suggesting a recent origin and high levels of gene flow in this species. The inference of a population expansion in the relatively recent past is supported by the mtDNA mismatch distribution analysis and the lineages-through-time-plot (Fig. 4). The mismatch distribution has a prominent major peak suggestive of a population expansion event (Rogers \& Harpending 1992). However, the curve is not perfectly smooth, which could be due to our small sample size or to a more complex population history (e.g. subdivision) after the inferred demographic growth. The convex shape of the lineagesthrough-time plot is also consistent with exponential population growth (Nee et al. 1994). But it also portrays a more recent period when this pattern is less visible, indicating that the demographic expansion may have been restricted to an earlier phase.

The microsatellite allele frequency distributions are also concordant with the inference of an expansion due to the fact that more than half of the variable loci show a unimodal or approximately unimodal pattern. The absence of such indications in 10 of the loci may reflect our small sample size or alternatively derive from demographic processes occurring after the hypothesized expansion. One of the 10 loci (FCA026) has a bimodal distribution that can be largely explained by dividing the jaguar sample in north-south geographical groups (not shown).

The $\mathrm{P}_{\mathrm{k}}$ distribution of our jaguar microsatellite data set is similar to the simulation results of Shriver et al. (1997) of either a population at equilibrium with an effective population size $\left(N_{\mathrm{e}}\right)$ around 1000 , or a population resulting from a 1000 -fold expansion $\approx 500$ generations ago. Although no strict comparisons should be attempted, it is almost certain that the $N_{\mathrm{e}}$ of jaguars as a species was, until very recently, much larger than 1000 . Therefore, this $P_{k}$ pattern is suggestive of a population which has still not reached equilibrium after an expansion event. The interlocus g-test result of less than one is also suggestive of population growth (Goldstein et al. 1999), although it seems to fall short of significance based on the critical value suggested by Reich \& Goldstein (1998) for a similar data set.

The estimated coalescence date of jaguar mtDNA haplotypes puts a lower bound on the origin of extant lineages around 137000 years ago, which indicates that the inferred population expansion happened around or before this time. This estimation suggested an origin 280 000-510 000 years ago, with an overall upper bound of 830000 years ago, still slightly younger than the confirmed fossil record of jaguars in north America (over 850000 years old; Seymour 1989). The phylogenetic relationships of jaguar mtDNA sequences (particularly Fig. 3) suggest that most extant lineages arose in northern South America, and that the colonization of Central America and Mexico was largely a subsequent process. This suggests that the postulated extinction of jaguars from most of North America towards the end of the Pleistocene left little residual genetic diversity, and that subsequent re-colonization occurred by immigration of South American founders.

The occurrence of two independent clades of jaguar mtDNA sequences occurring south of the Amazon River does not seem to indicate geographically segregated clusters, at least with the samples currently available. Rather, these clades seem to result from a recent colonization process of southern South America in which at least two unrelated founder haplotypes were present. This view is supported by the observation that these two clades have similar estimates of nucleotide diversity (not shown), and therefore can be interpreted as being of a similar age.

\section{Population structure}

Analyses of the genetic structure of jaguar populations showed no evidence of major geographical partitions, old subdivision events, or complete barriers to historical gene flow. This is consistent with the findings of Larson (1997), that were based on skull morphology, and in contrast with the traditional division of jaguar subspecies (reviewed by Seymour 1989). We could recognize up to four incompletely isolated phylogeographic partitions: Mexico + Guatemala, southern Central America, northern South America (north of the Amazon river), and southern South America (south of the river). These geographical groups are rather recent, however, and none demonstrated complete reciprocal monophyly in relation to the others (Figs 2, 3 and 5). Furthermore, the mtDNA data did not support the separation of Central America from northern South America, because the $F_{\mathrm{ST}}$ value derived from this marker was maximized when only two major phylogeographic groups (Southern and Northern) were considered (Table 4). On the other hand, the microsatellite data indicated higher levels of differentiation between Central America and northern South America than between northern and southern South America. In most cases, estimated levels of 
population differentiation were lower with the microsatellite data than with mtDNA (Table 4), which could be due to differences in the effective population size assessed by these two types of markers, and/or in the patterns of dispersal by male and female jaguars. Estimates of the number of migrants per generation $\left(N_{\mathrm{m}}\right)$ derived from mtDNA $F_{\mathrm{ST}}$ and microsatellite $F_{\mathrm{ST}}$ and $R_{\mathrm{ST}}$ values were high (around or above 1), but cannot be interpreted as a direct measure of current gene flow because they are also likely to be influenced by the recent common origin that these populations share.

The observed patterns can be interpreted as being caused by a combination of several demographic phenomena, starting with the recent expansion of the species as a whole, preventing sufficient time for extensive genetic differentiation. In addition, jaguars are able to disperse efficiently over broad areas and diverse habitats (Oliveira 1994), which is consistent with our inference of high levels of gene flow on wide geographical scales. The Amazon river may represent a historical barrier to gene flow predominantly in females, producing the only visible structure in the mtDNA phylogenies. However, the Amazon appears to have been less of an impediment for male dispersal, as inferred from our microsatellite data (Table 4, Fig. 5). This is in agreement with known aspects of the dispersal biology of felids in general, which indicate that females are largely philopatric and males are more likely to disperse longer distances (Kitchener 1991; Oliveira 1994). Our data also provide evidence for more recent barriers to gene flow between northern South America and southern Central America, and between Nicaragua and Guatemala, producing a measurable impact on the frequencies of microsatellite alleles and mtDNA haplotypes. Similar phylogeographic partitions that are likely caused by the same historical barriers have been observed for other Neotropical cat species, such as the puma (Culver et al. 2000), ocelot and margay (Eizirik et al. 1998). In addition to the inferred impact of localized historical barriers to gene flow, an overall pattern of isolation by distance over broad regions may also account for the observed patterns, and should be further investigated with additional sampling and refined geographical coverage.

\section{Implications for jaguar conservation}

These results have implications for the conservation and management of jaguars in the wild and in captivity. Genetic variability as estimated with mtDNA sequence diversity and microsatellite size variation are indicative of an outbred species with a somewhat recent origin, with no appreciable evidence for population- or species-level reduction in genetic variation.

The absence of deep geographical subdivision, the evidence for recent and incomplete isolation among major regions, and the inference of historically high levels of gene flow over broad areas argue for a revision of the traditionally held view of jaguar subspecies, which are usually the basis for conservation and management plans. Our data provide no support for the existence of major geographical partitions defining old, extensively isolated groups which could be viewed as subspecies or Evolutionary Significant Units (Ryder 1986; Moritz 1994). The only evidence for statistically significant geographical differentiation seems to support reduced levels of gene flow across barriers such as the Amazon river and the Darien Straits, and isolation by distance on a broad scale. Although the isolation generated by these localized barriers does not seem to be complete, management options which increase migration across them (e.g. field translocations or captive breeding of Amazonian individuals from the two sides of the river) should be avoided or minimized to approximate natural historical processes. Our results are compatible with currently favoured strategies for jaguar conservation on a broad regional basis (Medellín et al., in press), having largescale biomes or ecosystems as operational management units. This strategy is advisable both in terms of maintaining jaguars as an important component of functional ecosystems and as a flagship species for overall regional conservation. This management approach is also appropriate considering the possibility of local adaptation to different habitats, which would probably not be detected by our molecular markers (Lynch 1996), particularly given the number of samples analysed.

Finally, because of continued reduction, fragmentation and isolation of remaining jaguar populations, it is important to consider the inference presented here for high historical levels of gene flow over broad areas. Our results support management alternatives that permit the maintenance of this original and likely adaptive population dynamics, possibly including active intervention to mediate gene flow among isolated remnant populations.

\section{Acknowledgements}

We would like to express our thanks to all the people and Institutions that helped collect samples of biological material from jaguars, including those mentioned in Table 1, as well as C.B. Indrusiak, J.K. F. Mähler Jr., D.A. Sana, R.G. Morato, R. Gasparini-Morato, Companhia Energética de São Paulo (CESP) and Associação Pró-Carnívoros. We would like to thank L.R.P. Utz, S.L. Bonatto, N. Takezaki, C.B. Indrusiak, D.A. Sana, L. Cullen, R.J. Sarno, C.A. Driscoll, O. Uphyrkina, G. Bar-Gal, V.A. David, S. Cevario and A. Snyder for support, helpful information, discussions, suggestions and technical assistance. We also thank three anonymous reviewers for helpful suggestions and comments on a previous version of this paper. The American Association of Zoological Parks and Aquariums (AZA) and the Purina Conservation Endowment Fund (CEF) provided financial support for this research. E. Eizirik is supported by a fellowship from CNPq, Brazil. Samples of biological material were collected with the appropriate permits, and 
imported with a permit issued to the National Cancer Institute, National Institutes of Health (principal officer S.J. O'Brien).

\section{References}

Avise JC (1989) Role of molecular genetics in recognition and conservation of endangered species. Trends in Ecology and Evolution, 4, 279-281.

Avise JC (2000) Phylogeography: the History and Formation of Species. Harvard University Press, Cambridge.

Bonatto SL, Salzano FM (1997) A single and early migration for the peopling of the Americas supported by mitochondrial DNA sequence data. Proceedings of the National Academy of Sciences of the USA, 94, 1866-1871.

Boom R, Sol CJA, Salimans MMM et al. (1990) Rapid and simple method for purification of nucleic acids. Journal of Clinical Microbiology, 28, 495-503.

Bowcock AM, Ruiz-Linares A, Tomfohrde J et al. (1994) High resolution of human evolutionary trees with polymorphic microsatellites. Nature, 368, 455-457.

Culver M, Johnson WE, Pecon-Slattery J, O'Brien SJ (2000) Genomic ancestry of the American puma (Puma concolor). Journal of Heredity, 91, 186-197.

Driscoll CA (1998) A characterization of microsatellite loci variation in Panthera leo, Acinonyx jubatus and Felis concolor. MSc Thesis. Hood College, Frederick, MD, USA.

Eizirik E, Bonatto SL, Johnson WE et al. (1998) Phylogeographic patterns and mitochondrial DNA control region evolution in two Neotropical cats (Mammalia, Felidae). Journal of Molecular Evolution, 47, 613-624.

Excoffier L, Smouse PE (1994) Using allele frequencies and geographic subdivision to reconstruct gene trees within a species: molecular variance parsimony. Genetics, 136, 343-359.

Excoffier L, Smouse P, Quattro J (1992) Analysis of molecular variance inferred from metric distances among DNA haplotypes: application to human mitochondrial DNA restriction data. Genetics, 131, 479-491.

Felsenstein J (1985) Confidence limits on phylogenies: an approach using the bootstrap. Evolution, 39, 783-791.

Felsenstein J (1993) PHYLIP 3.5. Washington University, Seattle.

Goldstein DB, Roemer GW, Smith DA et al. (1999) The use of microsatellite variation to infer population structure and demographic history in a natural model system. Genetics, 151, 797-801.

Guo S, Thompson E (1992) Performing the exact test of HardyWeinberg proportion for multiple alleles. Biometrics, 48, 361-372.

Hillis DM, Bull JJ (1993) An empirical test of bootstrapping as a method for assessing confidence in phylogenetic analysis. Systematic Biology, 42, 182-192.

Jin L, Nei M (1990) Limitations of the evolutionary parsimony method of phylogenetic analysis. Molecular Biology and Evolution, 7, 82-102 (Published erratum appears in Molecular Biology and Evolution, 7, 201).

Johnson WE, Culver M, Iriarte A et al. (1998) Tracking the evolution of the elusive Andean Mountain Cat (Oreailurus jacobita) from mitochondrial DNA. Journal of Heredity, 89, 227-232.

Johnson WE, Dratch PA, Martenson JS, O'Brien SJ (1996) Resolution of recent radiations within three evolutionary lineages of Felidae using mitochondrial restriction fragment length polymorphism variation. Journal of Mammalian Evolution, 3, 97-120.

Johnson WE, O'Brien SJ (1997) Phylogenetic reconstruction of the Felidae using 16S rRNA and NADH-5 mitochondrial genes. Journal of Molecular Evolution, 44 (Suppl. 1), S98-S116.
Johnson WE, Pecon-Slattery J, Eizirik E et al. (1999) Disparate phylogeographic patterns of mitochondrial DNA variation in four closely related South American small cat species. Molecular Ecology, 8, S79-S94.

Kimura M (1980) A simple method for estimating evolutionary rate of base substitution through comparative studies of nucleotide sequences. Journal of Molecular Evolution, 16, 111-120.

Kitchener A (1991) The Natural History of the Wild Cats. Comstock/ Cornell, Ithaca.

Kumar S, Tamura K, Nei M (1993) MEGA, Version 1.1. The Pennsylvania State University, University Park, PA.

Larson SE (1997) Taxonomic re-evaluation of the jaguar. Zoo Biology, 16, 107-120.

Lavery S, Moritz C, Fielder DR (1996) Genetic patterns suggest exponential population growth in a declining species. Molecular Biology and Evolution, 13, 1106-1113.

Lopez JV, Cevario S, O'Brien SJ (1996) Complete nucleotide sequences of the domestic cat (Felis catus) mitochondrial genome and a transposed mtDNA tandem repeat (Numt) in the nuclear genome. Genomics, 33, 229-246.

Lynch M (1996) A quantitative-genetic perspective in conservation issues. In: Conservation Genetics: Case Histories from Nature (eds Avise JC, Hamrick JL), pp. 471-501. Chapman \& Hall, New York.

Medellín RA, Chetkiewicz C, Rabinowitz A et al. (eds) (2001) Jaguars in the new millennium: A status assessment, priority detection, and recommendations for the conservation of jaguars in the Americas. Universidad Nacional Autonoma de Mexico/Wildlife Conservation Society, Mexico D. F (in press).

Menotti-Raymond M, David VA, Lyons LA et al. (1999) A genetic linkage map of microsatellites in the domestic cat (Felis catus). Genomics, 57, 9-23.

Michalakis Y, Excoffier L (1996) A generic estimation of population subdivision using distances between alleles with special reference to microsatellite loci. Genetics, 142, 1061-1064.

Minch E (1997) MICROSAT 1.5d. Stanford University, http:// lotka.stanford.edu/microsat.html.

Montgomery GW, Sise JA (1990) Extraction of DNA from sheep white blood cells. New Zealand Journal of Agricultural Research, 33, 437-441.

Moritz C (1994) Defining 'Evolutionarily Significant Units' for conservation. Trends in Ecology and Evolution, 9, 373-375.

Nee S, May RM, Harvey PH (1994) The reconstructed evolutionary process. Philosophical Transactions of the Royal Society (London) B, 344, 305-311.

Nei M (1987) Molecular Evolutionary Genetics. Columbia University Press, New York.

Nei M, Jin L (1989) Variances of the average numbers of nucleotide substitutions within and between populations. Molecular Biology and Evolution, 6, 290-300.

Nowell K, Jackson P (1996) Wild Cats: status survey and conservation action plan. IUCN/SSC Cat Specialist Group, Gland, Switzerland.

O'Brien SJ (1994) A role for molecular genetics in biological conservation. Proceedings of the National Academy of Sciences of the USA, 91, 5748-5755.

Oliveira TG (1994) Neotropical cats: ecology and conservation. EDUFMA, São Luís, Brazil.

Pääbo S, Gifford JA, Wilson AC (1988) Mitochondrial DNA sequences from a 7000-year-old brain. Nucleic Acids Research, 16, 1245-1255.

Posada D, Crandall KA, Templeton AR (2000) GeoDis: a program for the cladistic nested analysis of the geographical distribution of genetic haplotypes. Molecular Ecology, 9, 487-488. 
Rambaut A, Harvey PH, Nee S (1997) End-Epi: An application for inferring phylogenetic and population dynamical processes from molecular sequences. Computer Applications in the Biosciences, 13, 303-306.

Reich DE, Goldstein DB (1998) Genetic evidence for a Paleolithic human population exansion in Africa. Proceedings of the National Academy of Sciences of the USA, 95, 8119-8123.

Rice WR (1989) Analyzing tables of statistical tests. Evolution, 43, 223-225.

Rogers AR, Harpending H (1992) Population growth makes waves in the distribution of pairwise genetic differences. Molecular Biology and Evolution, 9, 552-569.

Ryder OA (1986) Species conservation and systematics: the dilemma of subspecies. Trends in Ecology and Evolution, 1, 9-10.

Saiki RK, Scharf S, Faloona F et al. (1985) Enzymatic amplification of beta-globin genomic sequences and restriction site analysis for diagnosis of sickle cell anemia. Science, 230, 1350-1354.

Saitou N, Nei M (1987) The neighbor-joining method: a new method for reconstructing phylogenetic trees. Molecular Biology and Evolution, 4, 406-425.

Salles LO (1992) Felid phylogenetics: extant taxa and skull morphology (Felidae, Aeluroidea). American Museum Novitates, $3047,1-67$.

Sambrook J, Fritsch EF, Maniatis T (1989) Molecular Cloning: a Laboratory Manual. 2nd edn. Cold Spring Harbor Laboratory Press, New York.

Schneider S, Kueffer JM, Roessli D, Excoffier L (1997) ARLEQUIN, Version 1.1. University of Geneva, Switzerland. (http://lgb.unige.ch/ arlequin)

Seymour KL (1989) Panthera onca. Mammalian Species, 340, 1-9.

Shriver MD, Jin L, Ferrel RE, Deka R (1997) Microsatellite data support an early population expansion in Africa. Genome Research, 7, 586-591.

Slatkin M (1995) A measure of population subdivision based on microsatellite allele frequencies. Genetics, 139, 457-462.

Strimmer K, Von Haeseler A (1996) Quartet puzzling: a quartet maximum likelihood method for reconstructing tree topologies. Molecular Biology and Evolution, 13, 964-969.

Swofford DL (1998) PAUP* Phylogenetic Analysis Using Parsimony and Other Methods, Computer Program. Sinauer, Sunderland, MA.

Takezaki N, Rzhetsky A, Nei M (1995) Phylogenetic test of the molecular clock and linearized trees. Molecular Biology and Evolution, 12, 823-833.

Tamura K, Nei M (1993) Estimation of the number of nucleotide substitutions in the control region of mitochondrial DNA in humans and chimpanzees. Molecular Biology and Evolution, 10, $512-526$.
Templeton AR (1998) Nested clade analyses of phylogeographic data: testing hypotheses about gene flow and population history. Molecular Ecology, 7, 381-397.

Templeton AR, Routman E, Phillips CA (1995) Separating population structure from population history: a cladistic analysis of the geographical distribution of mitochondrial DNA haplotypes in the tiger salamander, Ambystoma tigrinum. Genetics, 140, 767-782.

Thompson JD, Gibson TJ, Plewniak F, Jeanmougin F, Higgins DG (1997) The ClustalX windows interface: flexible strategies for multiple sequence alignment aided by quality analysis tools. Nucleic Acids Research, 25, 4876-4882.

Turner A, Antón M (1997) The Big Cats and Their Fossil Relatives. Columbia University Press, New York.

Ward RH, Frazier BL, Dew-Jager K, Pääbo S (1991) Extensive mitochondrial diversity within a single Amerindian tribe. Proceedings of the National Academy of Sciences of the USA, 88, $8720-8724$

Weir BS, Cockerham CC (1984) Estimating F-statistics for the analysis of population structure. Evolution, 38, 1358-1370.

Wozencraft WC (1993) Felidae. In: Mammal Species of the World: a Taxonomic and Geographic Reference 2nd edn. (eds Wilson DE, Reeder DM), pp. 288-300. Smithsonian Institution Press/ American Society of Mammalogists, Washington.

Yang Z (1999) Phylogenetic Analysis by Maximum Likelihood (PAML), Version 2.0. University College London, London.

Yang Z, Kumar S (1996) Approximate methods for estimating the patterns of nucleotide substitution and the variation of substitution rates among sites. Molecular Biology and Evolution, 13, 650-659.

This study was part of a broad effort to characterize the genetic diversity, phylogenetic relationships and phylogeographic patterns of Neotropical felid species using molecular markers. Parallel studies on these species were performed addressing aspects of their reproductive physiology and exposure to infectious disease. The authors and several of their colleagues at the Laboratory of Genomic Diversity (LGD), National Cancer Institute, are studying the genetics of felids and other mammals to address issues such as phylogenetic reconstruction, genome evolution, hereditary and infectious disease, origin of phenotypic variation, and conservation of endangered species. Eduardo Eizirik is currently developing his Ph.D. at the LGD and the University of Maryland at College Park, on the genetics of coat colour variation in felids, which relates to this study in the context of the evolution of melanism in jaguar populations. 